\title{
Handbook for instructors of agriculture teacher trainees based on self-regulated learning framework
}

\author{
Sangnate Voraporn * \\ Bachelor of Education Program in Agriculture, Uttaradit Rajabhat University, Thailand.
}

Publication history: Received on 18 October 2019; revised on 10 December 2019; accepted on 11 December 2019

Article DOI: https://doi.org/10.30574/gscarr.2019.1.2.0010

\begin{abstract}
The objective of this study was to develop a handbook for instructors of agriculture teacher trainees based on selfregulated learning framework. The methodology consisted of 3 steps: 1) literature review; 2) development of a handbook for instructor; 3) evaluation of the handbook. The developed handbook composes 8 types of activities: 1) instructor development; 2) curriculum development; 3) learning support material development; 4) teaching and learning following the developed curriculum; 5) teaching and learning outside of the developed curriculum; 6) teaching and learning based on community participation; 7) trainees' practice teaching and orientating real students; 8) trainee evaluation.
\end{abstract}

Keywords: Teacher education; Handbook; Teacher production; Agriculture teacher; Self-regulated learning

\section{Introduction}

Today, Thailand has developed a fair share of various industries, but agriculture still plays an important role. As a matter of fact, government policies relating to agriculture has been elevated to be several of the most important policies for developing the country by every recent Thai government. They have supported agriculture as a unique characteristic of Thailand in the global community. For example, they have established a policy to make Thailand the 'kitchen of the world' and supported several southern provinces to be an important producer of global Halal food. These policies and supports show that agriculture in Thailand is full of growth potential. Therefore, production of quality personnel in agriculture demands serious and constant consideration, especially the production of agriculture teachers. These teachers not only help produce other agriculture personnel of the whole agricultural system but also work closely with communities, coordinating their effort with that of the government effectively. Hence, the production of agriculture teacher should be systematic, of high quality, and up to the same standard everywhere in the country.

The official agriculture teacher production in Thailand was established for a century in 2017. The first production effort started from an establishment of a Hor Wang primary school for producing agriculture teachers to teach in other agriculture schools as well as in general primary and secondary schools. The effort has been further extended and improved to suit the circumstance that the country faced at a particular time. Curriculums have been continuously improved to be in harmony with the demand of the time with the goal of sustainable production of quality agriculture teachers who would serve the communities, the society, and the country well [1]; [2]. At present, agriculture teacher production is done through 5 higher education institutes under the patronage of the government: 1) Rajabhat University of Chiangmai; 2) Rajabhat University of Surin; 3) Rajabhat University of Uttaradit; 4) Rajabhat University of Petchburi; and 5) King Mongkut's Institute of Technology Ladkrabang. Actually, many other universities have wanted to be a part in the agriculture teacher production, but they lack qualified instructors. Other factors also play a role in limiting the number of universities that offer agriculture teacher courses such as insufficient readiness of students, insufficient

\footnotetext{
${ }^{*}$ Corresponding author

E-mail address: voraporn2514@yahoo.com
} 
supports for teacher trainee education, constant curriculum changes, demand of contemporary teaching and learning to keep up with the evolution of the society, lack of modern, clear, and up to the same standard monitoring of teaching and learning process, and most importantly, insufficient consideration and support of agriculture teacher production from university executives. Therefore, a comprehensive handbook for instructors of agriculture teacher trainees is in much need as a key factor for resolving this issue.

Self-regulated Learning (SRL) is a cognitive framework in psychology that applies a meta-cognition concept to individuals so that they can learn, monitor their learning, and control their own learning by themselves. It can be facilely used to develop the quality of teachers. This framework can inform the practitioners of their cognitive and practical problem-solving abilities [3]; [4]; [5]. It is based on the social cognitive theory that aims for the practitioners to achieve the following: 1) self-observation, resource-evaluation, and self-conduct to reach their aim; 2) self-judgment: successful evaluation of own readiness and resources whether they are sufficient to reach the aim and in order to formulate effective strategies to achieve the aim; 3) self-reaction: evaluation of the results of self-judgment to see whether the aim has been achieved [6]. To conclude, SRL is a learning framework that allows teachers to control the development of their own teaching ability.

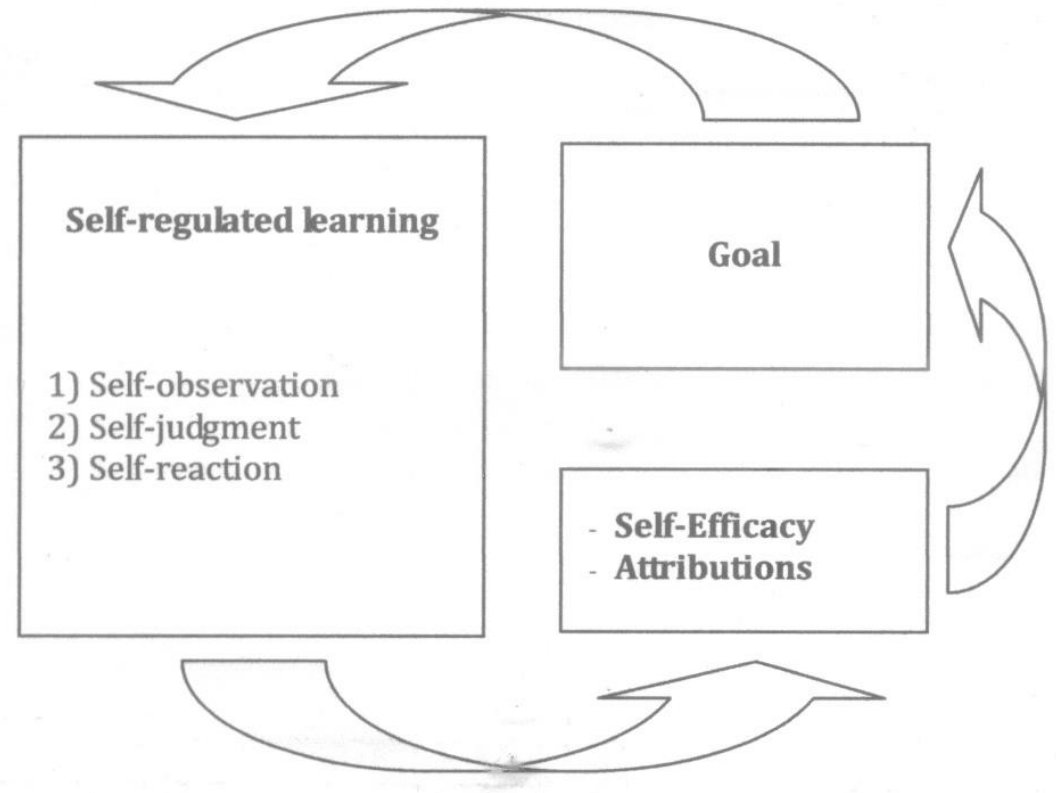

Figure 1 Cycle of self-regulated learning according to the social cognitive theory [6]

Up to today, there is still no actual handbook for instructors of agriculture teacher trainees in Thailand that can be used to provide instructor training to the same high standard. Therefore, this work aimed to develop such handbook based on self-regulated learning framework to be a guideline for instructors of agriculture teacher trainees and for executives of higher-education institutes to consistently produce quality bachelor degree agriculture teachers.

\section{Material and methods}

This work on development of a handbook for instructors of agriculture teacher trainees based on self-regulated learning framework was done in the following 3 steps: 1) analysis of information related to agriculture teacher production and self-regulated learning framework found in the literature; 2) development of the handbook; 3) evaluation of the handbook.

\subsection{Analysis of information related to agriculture teacher production and self-regulated learning framework found in the literature}

This step was mainly documentary research and investigation of the concepts, principles, and theories related to these two main topics as follows: a) the topic of arrangement of agriculture teacher education in Thailand [7]; [8]; b) the topic of arrangement of agriculture teacher education overseas; c) the concept of 21st century skills, d) the laws and regulations (2013) of the Teacher Council of Thailand regarding professional standards and ethics; e) the self-regulated learning framework. 


\subsection{Development of a handbook for instructors of agriculture teacher trainees based on self-regulated learning framework}

The handbook was developed to be consisted of activities that enable instructors to develop their own successful teaching and learning methods. Each activity was constructed based on a slightly-modified self-regulated learning (SRL) framework and consisted of 4 steps: a) Self-observation: instructors evaluate their knowledge and skills of the topics in the activity to see whether these are sufficient for them to take the next developmental step; b) Self-development: instructors select their own developmental method to achieve the goal concerning the topics under each activity; for example, under the activity of capability improvement for teacher profession is a topic of modern teaching and learning methods. Instructors may select workshop as their preferred developmental method; c) Self-action: instructors make the developmental method that they have selected happen by themselves; for example, an instructor who prefers to join a workshop on modern teaching and learning methods may request his or her institute to offer one and enroll in it; d) Self-reaction: instructors evaluate their development whether they have reached the goal that they had set; if they deem it successful, they move on to the next activity; if not, they repeat the first step and try out a new developmental method.

The following are the 8 types of activities in the handbook: a) instructor development; b) curriculum development; c) learning support material development; d) teaching and learning following the developed curriculum; e) teaching and learning outside of the developed curriculum; f) teaching and learning based on community participation; g) trainees' practice teaching and orientating real students; $h$ ) trainee evaluation. The cycle of agriculture teacher production is depicted in Figure 2.

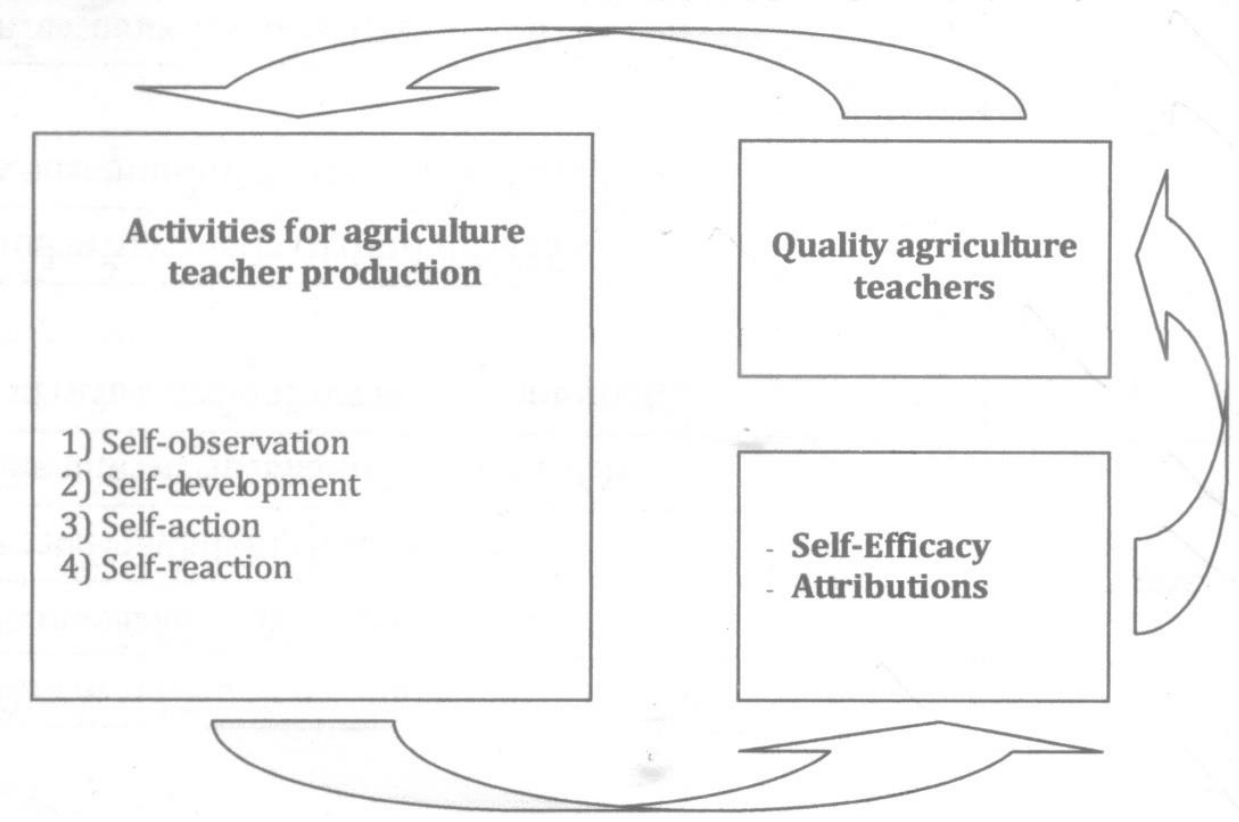

Figure 2 Cycle of Agriculture teacher production based on self-regulated learning framework

\subsection{Handbook evaluation}

The handbook was evaluated by 5 experts on 2 topics: a) the suitability of the activities and their content; b) the feasibility of using these activities and their content in actual practice. These 5 experts were highly experienced instructors of agriculture teacher trainees from each of the 5 institutes mentioned above. They evaluated the handbook by the following criteria: the scoring for each activity proposed in the handbook was based on the suitability and feasibility of using that activity in actual practice on a scale of 1 to 5 ( 1 is the lowest; 5 is the highest). The scores for each activity from all 5 experts were statistically analyzed into 5 classes [9] as follows: class interval was calculated by the following equation, the interval obtained for a class was 0.80 , and the scores in the 5 classes were the following:

A score between $1.00-1.80$ meant that the activity was the least suitable or feasible;

A score between $1.81-2.60$ meant that the activity was suitable or feasible at a low level;

A score between 2.61 - 3.40 meant that the activity was moderately suitable or feasible;

A score between $3.41-4.20$ meant that the activity was highly suitable or feasible; and 
A score between 4.21 - 5.00 meant that the activity was the most suitable or feasible.

\section{Results}

This section describes in detail each of the 8 types of the developed activities and its level of suitability as evaluated by the experts.

\subsection{Instructor development activity}

The objective of this activity is to develop instructors that are fully able to provide adequate teaching and learning environment for agriculture teacher trainees. At the end of their development, they should possess full abilities in the following aspects: a) knowledge and skills of agriculture teacher profession; b) knowledge and skills of agriculture profession; c) management skill; d) public relations; e) good physical and mental attributes. This main activity includes the following secondary activities: a) Activities for developing knowledge and skills of agriculture teacher profession; b) Activities for developing knowledge and skills of agriculture profession; c) Activities for developing management skill; d) Activities for developing public relations skill; e)Activities for developing good physical and mental attributes.

\subsection{Curriculum development activity}

The objective of this activity is for instructors to be able to develop adequate curriculum for agriculture teacher trainees who will be teaching in primary and secondary schools or vocational agriculture college. The secondary activities under this activity are the following: a) An activity for providing knowledge and skills for content creation in agriculture teacher trainee curriculum; b) An activity for providing knowledge and skills in teaching schedule administration for agriculture teacher trainee curriculum; c) An activity for providing knowledge and skills in trainee evaluation system for such curriculum.

\subsection{Learning support material development activity}

The objective of this activity is for instructors to be able to develop better learning support materials to meet a high standard. The learning support materials in this sense are facilities and devices that support teaching and learning, e.g., classroom, laboratory, published material, and tractor. The secondary activities covered by this main activity are the following: a) Activity for development of administration system of department/faculty/institute in order for them to make available proper supporting materials; b) Activity for acquisition of sufficient amount of proper supporting materials; c) Activity for development of previous learning support materials of which were evaluated to need improvement.

\subsection{Activity for teaching and learning following the developed curriculum}

The objective of this activity is for instructors to be able to develop teaching and learning techniques for trainees that are appropriate to their level-primary and secondary schools or vocational agriculture college-and for trainees to possess good qualities after they have graduated such as the teacher's qualities and ethics specified in the teacher profession standards issued by the Education Council of Thailand (2013) and the 21st-century teacher skills as expounded in [10]. The secondary activities covered by this activity are the following: a) Activity for promoting instructors' understanding of the objectives of the teaching and learning activities for trainees; b) Activity for promoting the preparation of lessons to trainees before they are implemented; c) Activity for promoting the variety of teaching and learning formats; d) Activity for promoting the teaching and learning techniques; e) Activity for promoting the evaluation of teaching and learning after they have been done.

\subsection{Activity for teaching and learning outside of the developed curriculum}

The objective of this activity is for instructors to develop their own knowledge and skills such that they can transfer adequate knowledge and skills to the trainees. There are 5 secondary activities under this activity: a) Activity for promoting instructors' understanding of the objectives of the teaching and learning activities for trainees; b) Activity for promoting the preparation of lessons to trainees before they are implemented; c) Activity for promoting the variety of teaching and learning formats; d) Activity for promoting the teaching and learning techniques; e) Activity for promoting the evaluation of teaching and learning after they have been done.

\subsection{Activity for teaching and learning based on community participation}

The objective of this activity is for instructors to acquire the wisdom of the surrounding communities and the realization of the significance of the communities to the institute and the society and to transfer them to the trainees. There are 5 
secondary activities under this main activity: a) Activity for promoting instructors' understanding of the objectives of the teaching and learning activities for trainees; b) Activity for promoting the preparation of lessons to trainees before they are implemented; c) Activity for promoting the variety of teaching and learning formats; d) Activity for promoting the teaching and learning techniques; e) Activity for promoting the evaluation of teaching and learning after they have been done.

\subsection{Activity for instructors' practice teaching and orientating real trainees}

The objectives of this activity are for instructors to deeply understand the role of orientation instructors in orienting trainees and for them to acquire real experiences in teaching. There is one secondary activity under this activity: Activity for development of orientation instructors who will be orienting trainees at the initial stage of their training.

\subsection{Activity for trainee evaluation}

The objective of this activity is for instructors to be able to successfully perform all kinds of evaluation of the trainees. There are 6 secondary activities under this activity: a) Activity for promoting instructors' deep understanding of the various attributes of evaluation; b) Activity for promoting instructors' understanding of evaluation methods; c) Activity for promoting instructors' understanding of evaluation criteria; d) Activity for promoting instructors' understanding of the attributes and formats of evaluation of agriculture teacher trainees; e) Activity for promoting instructors' understanding of the evaluation of trainees' works; f) Activity for promoting instructors' understanding of the evaluation of the trainees' physical and mental abilities.

The complete evaluation of this handbook by 5 experts consisted of evaluations of every activity and its content. In addition, each of these evaluations included an evaluation of the level of its suitability and its feasibility for use in actual practice. The evaluation results showed that the level of the suitability and feasibility of every activity was at a high level, one level below the highest level, as shown in Table 1.

Table 1 Results of evaluation of the handbook for instructors of agriculture teacher trainees by 5 experts

\begin{tabular}{lllll}
\hline Item & & Mean score & SD. & Level \\
\hline Activity & Suitability & 4.20 & 0.83 & High \\
& Feasibility & 4.00 & 0.70 & High \\
Content & Suitability & 4.20 & 0.44 & High \\
& Feasibility & 4.09 & 0.46 & High \\
\hline
\end{tabular}

\section{Discussion}

The handbook for instructors of agriculture teacher trainees was developed systematically to contain activities that were subsequently proven to be suitable and feasible. As can be observed in an example of the activities in the appendix, self-regulated learning principles were used to drive each activity as expounded in the Methodology section above. It can be seen that the activity encourages, if not demands, instructors to drive the activity, direct it and freely performing it by themselves as allowed by the readiness of their institute and supports from the surrounding factors. It is as if instructors were the owner of their learning process because they would be the ones who plan out their own learning methods and evaluate the outcomes, all by themselves, not by their institute. To conclude, all of the activities in the handbook follow strictly the slightly modified self-regulated learning framework proposed by Pintrich [3] and Schunk [6]. Moreover, the results of high level in suitability and feasibility of all evaluated activities in the handbook by 5 highly experienced instructors from all institutes that offer an agriculture teacher curriculum in Thailand confirm that selfregulated learning framework is appropriate for driving the system of agriculture teacher production.

Table 2 demonstrates how the activities in the handbook reflect the self-regulated learning framework that they are based on. The self-observation step in the handbook is the initial step in self-regulated learning framework. The rationale behind this step is that when a person knows his or her capabilities well, he or she will be more strongly motivated to persevere toward the goal than a person who does not know them well [11]. 
Table 2 Demonstration of how the activities in the handbook reflect the self-regulated learning framework that they are based on

\begin{tabular}{|c|c|c|c|}
\hline \multicolumn{2}{|c|}{ Activity of Self-regulated learning } & \multicolumn{2}{|c|}{ Activity of the handbook } \\
\hline Step & Objective & Step & Objective \\
\hline 1) Self-observation & $\begin{array}{l}\text { To evaluate the level of } \\
\text { one's knowledge and } \\
\text { skills }\end{array}$ & 1) Self-observation & $\begin{array}{l}\text { Instructors evaluate } \\
\text { themselves where the } \\
\text { outcomes will show the } \\
\text { capabilities that they } \\
\text { have at that point in } \\
\text { time }\end{array}$ \\
\hline \multirow[t]{2}{*}{ 2) Self-judgment } & $\begin{array}{l}\text { To select their own } \\
\text { methods for further } \\
\text { developing their } \\
\text { capabilities }\end{array}$ & 2) Self-development & $\begin{array}{l}\text { Instructors select their } \\
\text { own learning methods } \\
\text { where the outcomes } \\
\text { will be selected forms } \\
\text { or formats of } \\
\text { developmental } \\
\text { methods }\end{array}$ \\
\hline & & 3) Self-action & $\begin{array}{l}\text { Instructors are trained } \\
\text { by the selected } \\
\text { methods arranged by } \\
\text { their institute }\end{array}$ \\
\hline 3) Self-reaction & $\begin{array}{l}\text { To evaluate the results of } \\
\text { their development }\end{array}$ & 4) Self-reaction & $\begin{array}{l}\text { Instructors evaluate } \\
\text { themselves after they } \\
\text { have been trained } \\
\text { where the outcomes } \\
\text { will be the level of } \\
\text { utility of the knowledge } \\
\text { and skills that they } \\
\text { have acquired }\end{array}$ \\
\hline
\end{tabular}

The next step is instructors' selection of their preferred developmental methods [4]. The handbook suggests the following methods: training, seminar and field trip. This step and the next self-action step of actual practice according to the selected developmental methods are expansion on the self-judgment step in the original SRL. The self-action step was added to make it clear to the executives of Thailand's institutes of the role of the institutes in arranging the developmental methods for instructors because each institute in Thailand has a different vision, mission and readiness in instructor production so its ability to satisfy a request for a selected developmental method may be quite different.

The last step, self-reaction, agrees with a statement by [4] that after-development evaluation enables a person to correctly perceive his or her progress and effort. It also agrees with a statement by [12]; [13] that the main point of SRL is that a learner can choose, organize and use various cognitive methods for development by himself or herself.

\section{Conclusion}

This study was a design and development of a handbook for instructors of agriculture teacher trainees based on selfregulated learning framework. It was developed because of the lacking of a systematic and effective guideline for producing instructors of agriculture teacher trainees in Thailand. The handbook was designed to base on self-regulated learning framework because the framework has been widely accepted as highly effective for development of learners' capabilities. The results of this study were 8 types of activities for developing instructors of agriculture teacher trainees that were approved by five highly experienced instructors of such trainees from all five institutes in Thailand that offer an agriculture teacher degree. 


\section{Appendix}

The following is a concise example of an activity for developing knowledge and skills of agriculture teacher profession:

\subsection{Before performing the activity}

Objective: to develop the knowledge and skills of instructors to be able to teach the trainees effectively and be a good example for them.

\subsection{In the activity}

a) A self-observation of his or her own knowledge and skills on teaching agriculture.

A form for self-observation of one's own knowledge and skills on teaching agriculture.

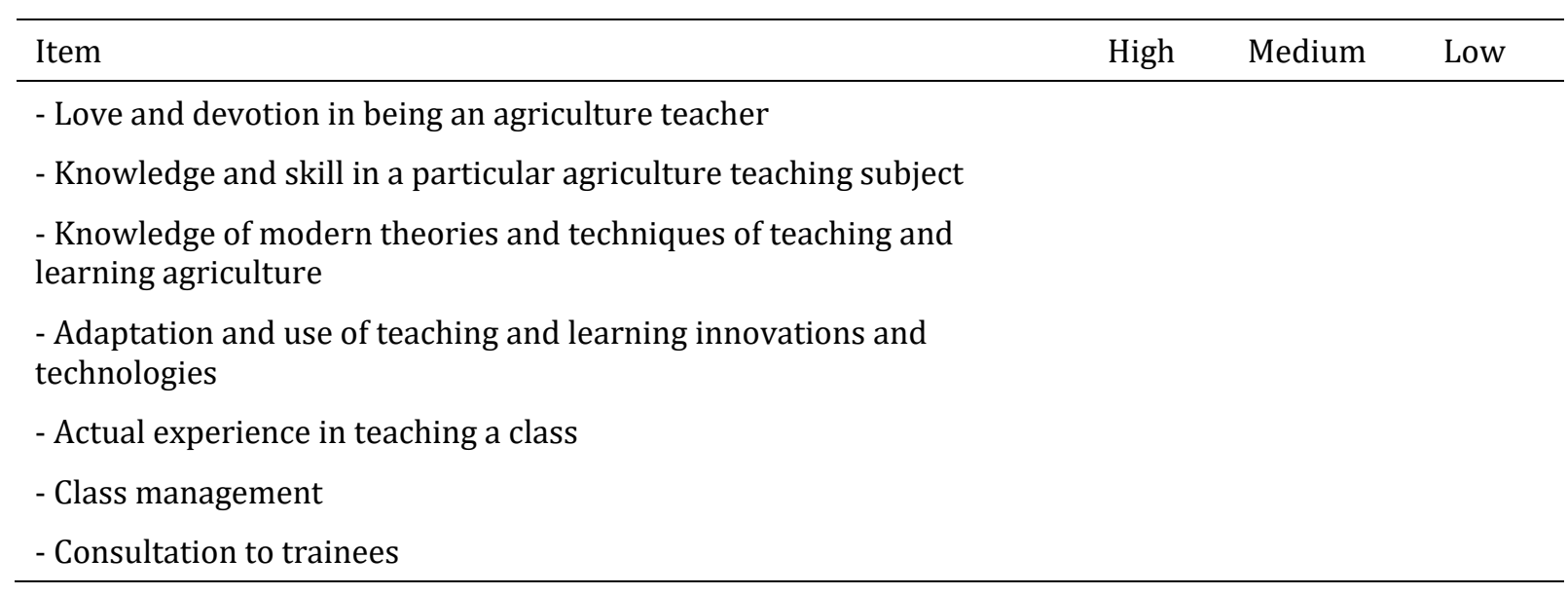

b) Self-development of knowledge and skills of agriculture teacher

A form for self-development of knowledge and skills of agriculture teacher

\begin{tabular}{|c|c|c|c|c|c|c|}
\hline \multirow[t]{2}{*}{ Priority } & \multirow[t]{2}{*}{ Item } & \multicolumn{4}{|c|}{ Development format } & \multirow[t]{2}{*}{ Note } \\
\hline & & Training & Seminar & $\begin{array}{l}\text { Field } \\
\text { trips }\end{array}$ & Others & \\
\hline & $\begin{array}{l}\text { - Love and devotion in being an agriculture } \\
\text { teacher }\end{array}$ & & & & & \\
\hline & $\begin{array}{l}\text { - Knowledge and skill in a particular agriculture } \\
\text { teaching subject }\end{array}$ & & & & & \\
\hline & $\begin{array}{l}\text { - Knowledge of modern theories and techniques } \\
\text { of teaching and learning agriculture }\end{array}$ & & & & & \\
\hline & $\begin{array}{l}\text { - Adaptation and use of teaching and learning } \\
\text { innovations and technologies }\end{array}$ & & & & & \\
\hline & - Actual experience in teaching a class & & & & & \\
\hline & - Class management & & & & & \\
\hline & - Consultation to trainees & & & & & \\
\hline
\end{tabular}

c) Self-action: Instructors develop themselves according to the entries in the self-observation form above by practicing teaching at their own institute or another institute that they choose. 


\subsection{After the activity}

Self-reaction to the implemented actions according to the entries in the self-observation form above, i.e., self-evaluation of one's knowledge and skills after they have been developed whether they can utilize what they have developed well enough or not.

An evaluation form for self-development of knowledge and skills of agriculture teacher

\begin{tabular}{|c|c|c|c|c|c|}
\hline \multirow[t]{2}{*}{ Priority } & \multirow[t]{2}{*}{ Item } & \multicolumn{3}{|c|}{ Level of effectiveness } & \multirow[t]{2}{*}{ Note } \\
\hline & & High & Medium & Low & \\
\hline & - Love and devotion in being an agriculture teacher & & & & \\
\hline & $\begin{array}{l}\text { - Knowledge and skill in a particular agriculture } \\
\text { teaching subject }\end{array}$ & & & & \\
\hline & $\begin{array}{l}\text { - Knowledge of modern theories and techniques of } \\
\text { teaching and learning agriculture }\end{array}$ & & & & \\
\hline & $\begin{array}{l}\text { - Adaptation and use of teaching and learning } \\
\text { innovations and technologies }\end{array}$ & & & & \\
\hline & - Actual experience in teaching a class & & & & \\
\hline & - Class management & & & & \\
\hline & - Consultation to trainees & & & & \\
\hline
\end{tabular}

\section{Compliance with ethical standards}

\section{Acknowledgments}

The successful development of this handbook was possible because of the helps and supports from several research consultants; and several experts who assessment of this handbook.

\section{References}

[1] Siriwan N. (1989). Farm work: An important strategy of education in agriculture. Ponchai, Bangkok, THA, 42-43.

[2] Intorrathed S. (2013). Principles of agricultural education. Mean supply service, Bangkok, THA, 15-33.

[3] Pintrich PR. (2000). The Role of Goal Orientation in Self-Regulated Learning. In: Boekaerts M, Pintrich PR and Zeidner M (Eds.), Handbook of Self-Regulation. Academic Press, California, 451-502.

[4] Butler DL. (1998). The Strategic Content Learning Approach to Promoting Self-Regulated Learning with Learning Disability. In: Schunk DH and Zimmerman BJ (Eds.), Self - Regulated Learning From Teaching to Self-Reflective Practice. Guilford, New Jersey, 162-166.

[5] Boekaerts M and Corno L. (2005). Selfregulation in the classroom: A perspective on assessment and intervention. Applied Psychology: An International Review, 54(2), 199-231.

[6] Schunk DH. (1994). Self - Regulation of Self - Efficacy and Attributions In academic Setting. In: Schunk DH, \& Zimmerman BJ (Eds.), Self - regulation of learning and performance: issues and educational applications. Lawrence, New Jersey, 76-79.

[7] Sangnate V, Intorrathed S, Khemtong P and Poungsuk P. (2016). The Current Condition of Teaching and Learning on Agriculture Teachers Training of Thailand. Journal of Agricultural Technology, 12(5), 841-850.

[8] Sangnate V. (2019). Modern Guidelines of Teaching and Learning for Agriculture Teacher Production in Thailand. Acta Scientific Agriculture, 3(10), 195-203.

[9] Ruangprapan C. (2000). Basic statistics and examples of analyses with Minitab, SPSS and SAS. 5th edition, Khonkaen University, Khonkaen, THA, 30. 
[10] Panich W. (2012). Teaching pathway for learners of the 21st-century .Sodsri-Saritwong foundation, Bangkok, THA, 9-58.

[11] Hagen AS and Weinstein CE. (1995). Achievement Goals, Self-Regulated Learning and the Role of Classroom Context. In: Pintrich PR (Eds.), Understand Self-Regulated Learning. Jossey Bass Publisheers, San Francisco, 4345.

[12] Wolters AC (1999). The relation between high school students' motivational regulation and their use of learning strategies, afford, and classroom performance. Learning and Individual Differences, 3(3), 281-299.

[13] Schunk DH and Ertmer P. (2000). Self-regulation and academic learning: Self-efficacy enhancing interventions. In: Boekarts M, Pintrich PR and Zeidner M (Eds.), Handbook of Self-Regulation. Elsevier Academic Press, Massachusetts, 631-649.

\section{How to cite this article}

Sangnate V. (2019). Handbook for instructors of agriculture teacher trainees based on self-regulated learning framework. GSC Advanced Research and Reviews, 1(2), 01-09. 